\title{
Influence of Indentation on the Fatigue Strength of Carbonitrided Plain Steel
}

\author{
Jiewei Gao, ${ }^{1}$ Guangze Dai, ${ }^{1}$ Junwen Zhao, ${ }^{1}$ Hengkui Li, ${ }^{2}$ Lei Xu, ${ }^{3}$ and Zhenyu Zhu ${ }^{1}$ \\ ${ }^{1}$ School of Materials Science and Engineering, Southwest Jiaotong University, Chengdu 610031, China \\ ${ }^{2}$ CSR Qingdao Sifang Co., Ltd., Qingdao 266111, China \\ ${ }^{3}$ School of Materials Science and Engineering, Xihua University, Chengdu 610039, China \\ Correspondence should be addressed to Guangze Dai; g.dai@163.com
}

Received 21 May 2015; Revised 20 July 2015; Accepted 11 August 2015

Academic Editor: Massimiliano Barletta

Copyright (C) 2015 Jiewei Gao et al. This is an open access article distributed under the Creative Commons Attribution License, which permits unrestricted use, distribution, and reproduction in any medium, provided the original work is properly cited.

To study the influence of indentation on the fatigue strength of untreated and carbonitrided specimens of S38C steel, the fatigue limit of specimens with and without indentations was tested. Fracture surfaces were observed using scanning electron microscopy (SEM). The results show that the fatigue strength of the untreated specimen decreases with increasing dimension of indentation, without significant difference compared to the predicted results. Compared to the fatigue limit of the untreated specimen, those of the carbonitrided specimen and the carbonitrided specimen whose compound layer was polished were improved by $12 \%$ and $40 \%$, respectively. The fatigue strength of the carbonitrided specimen decreased sharply with increasing indentation size because of the presence of microcracks in the compound layer. When the compound layer was removed, the fatigue limit was observed to be less sensitive to indentation than that of the carbonitrided specimen.

\section{Introduction}

A large number of surface treatment methods have been developed with the target of hardening a material's surface and introducing compressive residual stress to enhance component service performance, such as corrosion resistance, fatigue resistance, wear resistance, or fretting resistance [1]. Nitriding and carbonitriding have been widely employed in modern manufacturing because of their energy conservation, environmental friendliness, high efficiency, good repeatability, and good flexibility [2]. Nitrogen and carbon atoms diffuse into the matrix, forming compounds with $\mathrm{Fe}$ or precipitates with alloy elements and also leading to lattice distortion. The strength of the material surface is hardened by the precipitates, and compressive stress is introduced by the expansion of the diffusion layer [3]. Cyclic slip of the surface material is arrested, and the high-cycle fatigue-crack initiation site usually shifts to the subsurface because of the surface hardening and residual compressive stress [4].

Generally, a carbonitrided layer comprises two layers: a compound layer (which sometimes includes an oxide layer) and a diffusion layer. The compound layer, also called the white layer, consists of $\gamma^{\prime}-\mathrm{Fe}_{4} \mathrm{~N}, \varepsilon-\mathrm{Fe}_{3} \mathrm{~N}$, or a mixture of both, depending on the carbonitriding conditions [5]. Because of its high hardness and electrochemical stability, this layer plays an important role in enhancing the wear resistance and corrosion resistance of treated materials; however, the diffusion layer rather than the compound layer plays a dominant role in determining the fatigue strength [6]. Undeniably, the roughness and brittleness of the compound layer and the micropores formed by the release of nitrogen molecules of the thicker compound layer detrimentally affect the fatigue strength and wear resistance of treated materials [7]. In the contact fatigue test or wear test, the compound layer fails by delaminating and breaking into pieces, which deteriorates the test conditions [8].

Carbonitriding has been demonstrated to decrease the notch sensitivity of notched specimens and to increase the fatigue strength of notched specimens by a large margin [9]. However, the literature contains few reports focused on the effect of surface defects on the fatigue behavior of carbonitrided specimens. Recently, the authors of two papers considered the influence of small artificial surface defects on the fatigue behavior of nitrided and shot-peened steel; 
TABLe 1: Chemical composition of S38C steel (mass fraction, \%).

\begin{tabular}{lcccccccc}
\hline $\mathrm{C}$ & $\mathrm{Si}$ & $\mathrm{Mn}$ & $\mathrm{P}$ & $\mathrm{S}$ & $\mathrm{Cr}$ & $\mathrm{Mo}$ & $\mathrm{Ni}$ & $\mathrm{Al}$ \\
\hline 0.39 & 0.29 & 0.81 & 0.008 & 0.006 & 0.097 & 0.024 & 0.039 & 0.013
\end{tabular}

however, they did not consider the effect of the compound layer [10]. Nitriding causes an appreciable reduction of the impact fatigue strength and the Charpy impact resistance [11]. The compound layer forms microcracks or breaks into pieces when impacted. The microcracks and notches formed by impact may negatively affect the fatigue strength of carbonitrided specimens. In this study, medium carbon steel was gas carbonitrided. The influence of indentation on the fatigue behavior of carbonitrided specimens $(\mathrm{CN})$ and carbonitrided specimens with the compound layer being polished (CNP) was studied and compared with the fatigue properties of an untreated specimen (UCN).

\section{Material and Methods}

Hourglass specimens with a minimal diameter of $10 \mathrm{~mm}$ were machined from a railway axle made from S38C steel (JIS); the specimen was machined along the axial direction. The steel of the specimens was plain steel; its chemical composition is presented in Table 1 . The ultimate tensile strength of the steel was UTS $=640 \mathrm{MPa}$, the monotonic yield strength $\sigma_{y}$ was $330 \mathrm{MPa}$, and the hardness was HV200. The surface of the specimen was mechanically polished to a mirror surface with a roughness less than $0.2 \mu \mathrm{m}$. Carbonitriding was performed in a mixture gas $\left(\mathrm{NH}_{3}, \mathrm{O}_{2}, \mathrm{C}_{2} \mathrm{H}_{2} \mathrm{OH}, \mathrm{H}_{2} \mathrm{O}\right.$, and $\left.\mathrm{N}_{2}\right)$ at $620^{\circ} \mathrm{C}$ for $2.5 \mathrm{~h}$ and then cooled in air. The indentation was performed using a hardness tester (HBE-3000A), as shown in Figure 1. The load was adjustable, and the diameter of the indenter used in the experiments was $1587.5 \mu \mathrm{m}$. The morphology of the indentation was examined using laser confocal microscopy (VK-9710K), and its geometric size was measured.

Cross sections of both untreated and treated specimens were polished and etched with $4 \%$ nital solution. The microstructure was observed using laser confocal microscopy. The hardness profile of the carbonitrided layer was measured on a micro-Vickers hardness tester (HVS$1000 \mathrm{Z}$ ) using an indentation load of $100 \mathrm{~g}$ for $15 \mathrm{~s}$. The thickness of carbonitrided layer was defined according to the hardness profile (50HV0.1 higher than that of the matrix). The oxide layer was very thin and easy to polish away to expose the compound layer. The specimen for phase analysis of the diffusion layer was ground and polished to a mirror finish, and the thickness of the specimen was checked using a micrometer. The phase was analyzed using a Philips X'Pert PRO $\mathrm{X}$-ray diffractometer $\left(\mathrm{Cu}-\mathrm{K}_{\alpha}\right.$ radiation source, $\left.\lambda=1.544 \AA\right)$.

Fatigue tests were conducted by employing a resonance fatigue tester (GPS-100). The load was variable over the range from 0.1 to $100 \mathrm{kN}$, and the index value was $0.002 \mathrm{kN}$. The fatigue tests were performed with a sinusoidal stress wave and an axial tension-compression stress ratio of $R=-1$. The cyclic frequency was $140 \mathrm{~Hz}$. The number of run-out cycles was set at $5 \times 10^{6}$. Staircase tests were performed, and the

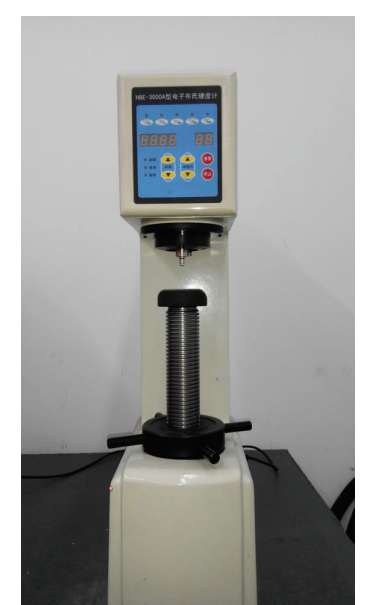

FIGURE 1: Hardness tester used for creating indentations.

fatigue limit $\sigma_{w 0}$ was calculated according to (1), where $\sigma_{i}$ $(i=1$ to $n / 2)$ is the sum of the fatigue limit of two specimens in $n / 2$ paired specimens. Sixteen to twenty specimens were tested for each type of specimen to obtain the fatigue limit. The fractured surfaces of the specimens were observed using scanning electron microscopy (SEM, JEOL-7001). Consider

$$
\sigma_{w 0}=\frac{1}{n} \sum \sigma_{i}
$$

\section{Results and Discussion}

3.1. Characterization of the Specimens. The matrix microstructure of S38C consists of pearlite and ferrite (Figure 2(a)), without variation after carbonitriding (Figure 2(b)). The microstructure of the $\mathrm{CN}$ can be divided into three layers from the surface to the core: the oxide layer, the compound layer, and the diffusion layer. The oxide layer is relatively thin, approximately $5 \mu \mathrm{m}$, whereas the compound layer is $35 \mu \mathrm{m}$. The microhardness of the compound layer is 580HV0.1. With increasing depth, the hardness decreases sharply from 580HV0.1 to $366 \mathrm{HV} 0.1$ and then gradually approaches the hardness of the core. According to the microhardness profile (Figure 3), the total thickness of the carbonitrided layer is $450 \mu \mathrm{m}$ ( $50 \mathrm{HV}$ greater than the hardness of the core). As shown in Figure 4, the oxide layer of the $\mathrm{CN}$ consists of $\mathrm{Fe}_{2} \mathrm{O}_{3}$ and $\mathrm{Fe}_{3} \mathrm{O}_{4}$ (Figure 4(a)), and the main phases of the compound layer are $\mathrm{Fe}_{4} \mathrm{~N}$ and $\mathrm{Fe}_{2-3} \mathrm{~N}$ (Figure 4(b)). The diffraction pattern shows that the diffusion layer is $\alpha$-Fe (Figure 4(c)), without differences with the matrix (Figure 4(d)).

Figure 5 shows the morphologies of the indentations on three types of specimens. According to the microstructure and phase composition of the matrix, shown in Figures 2(a) and 4(d), S38C is ductile and can be deformed easily. During the formation of indentations, the matrix underwent plastic deformation. Figure 5(a) illustrates the indentation on the UCN formed by a force of $100 \mathrm{~N}$. The hump is obvious on the edge of the indentation, but no secondary defects, for 


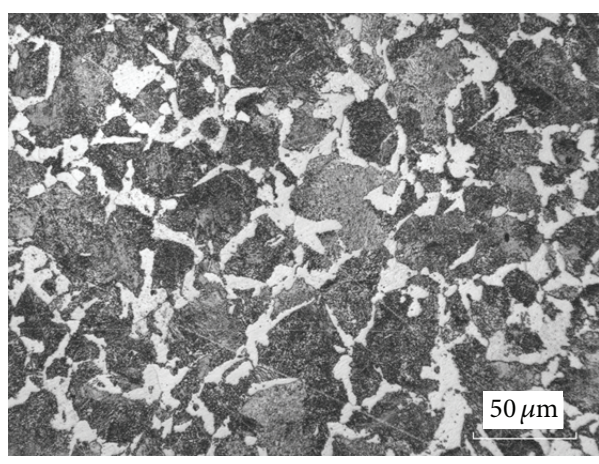

(a)

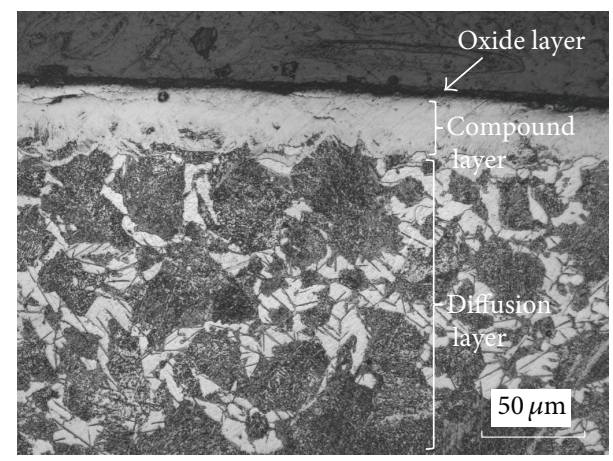

(b)

Figure 2: Microstructures of the (a) UCN and (b) CN.

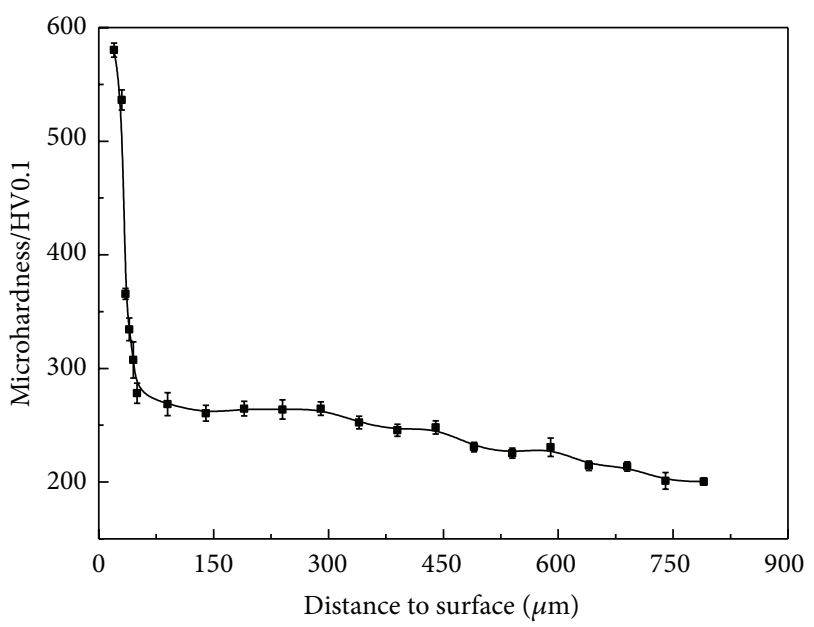

FIgURE 3: Microhardness profile of the CN.

example, microcracks, are observed. The surface of the $\mathrm{CN}$ is covered with iron nitrides, which are hard and brittle, as illustrated in Figures 2(b) and 3. The compound layer cracks even when the indentation is smaller, resulting in radialmedian microcracks (Figure 5(b)). When the indentation of the $\mathrm{CN}$ is larger, the density of microcracks on the surface of the indentation increases and the radial microcracks also appear around the indentation of the CN (Figure 5(c)). The morphology of indentation of the CNP is similar to that of the UCN (Figure 5(d)), and even the diffusion layer is hardened.

3.2. Results of the Fatigue Tests. As evident in Figure 6, the fatigue limit of the smooth UCN is $250 \mathrm{MPa}$. The fatigue limit of the indented UCN decreases slightly with increasing projected area of the indentations. If the indentation is considered as a defect, such as a surface inclusion, then the fatigue limit can be obtained according to equation proposed by Murakami and Usuki (see (2)) [12]. Consider

$$
\sigma=\frac{1.43 \cdot(\mathrm{HV}+120)}{(\sqrt{\text { area }})^{1 / 6}}
$$

where $\sigma$ is the tension-compression fatigue limit of the indented specimen ( $\mathrm{MPa}), \mathrm{HV}$ is Vickers hardness $\left(\mathrm{kgf} \mathrm{mm}^{-2}\right)$, and area is the projected area of indentation $\left(\mu \mathrm{m}^{2}\right)$ on the cross section perpendicular to the axial direction. The theoretical value in Figure 6 appears to be greater than that obtained by experiment; however, the largest disparity was less than $3 \%$.

The fracture surface of the smooth specimen of UCN can be divided into three zones (Figure $7(\mathrm{a})$ ): the initiation site, the crack propagation zone, and the final fracture zone. The crack initiated from the surface and propagated into the specimen perpendicular to the specimen surface (Figure 7(b)). In the case of the indented UCN, its fracture surface is similar to that of the smooth specimen (Figure 8(a)); however, the crack initiates from the bottom of the indentation because of the local plastic deformation caused by cyclic stress concentration (Figure 8(b)).

During the formation of the indentation on the UCN, the indented site undergoes plastic deformation, as shown in Figure 5. The local region was hardened by the plastic deformation around the indentation, and residual compressive stress was introduced by plastic deformation (as analyzed by the finite element method, and consistent with the study results of Bagherifard et al. [13]). However, the indentation, which is a type of geometrical discontinuity, deteriorates the fatigue limit of the indented specimen because of stress concentration. The fatigue limit decreases with increasing defect size, and the relationship of the fatigue limit to the defect size is given by (2) proposed by Murakami and Usuki [12]. Taking surface hardening and residual compressive stress into consideration, we expected the fatigue limit of the indented specimens to be higher than the theoretical values calculated on the basis of the matrix hardness and the projected area of the defect [14]. In fact, no significant differences exist between the values (Figure 6). First, the largest indentation depth is less than $200 \mu \mathrm{m}$, and the diameter is less than $1000 \mu \mathrm{m}$. Unlike shot peening [13], the depth and breadth of the deformation volume around the indentation are small and local hardening does not significantly contribute to the fatiguecrack initiation resistance and crack propagation resistance. In addition, the relaxation of the residual compressive stress is an irresistible process under cyclic stress, especially under 


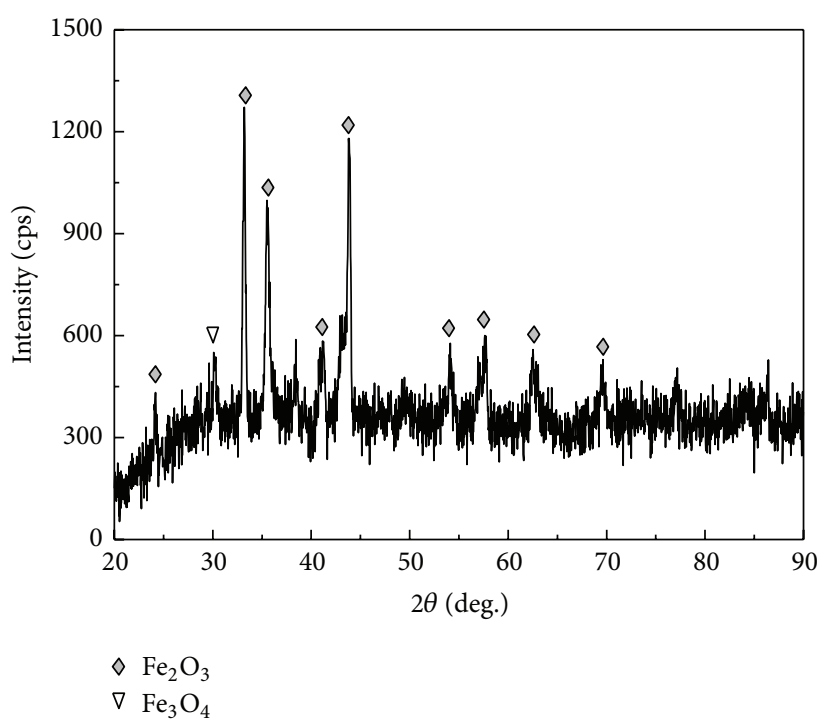

(a)

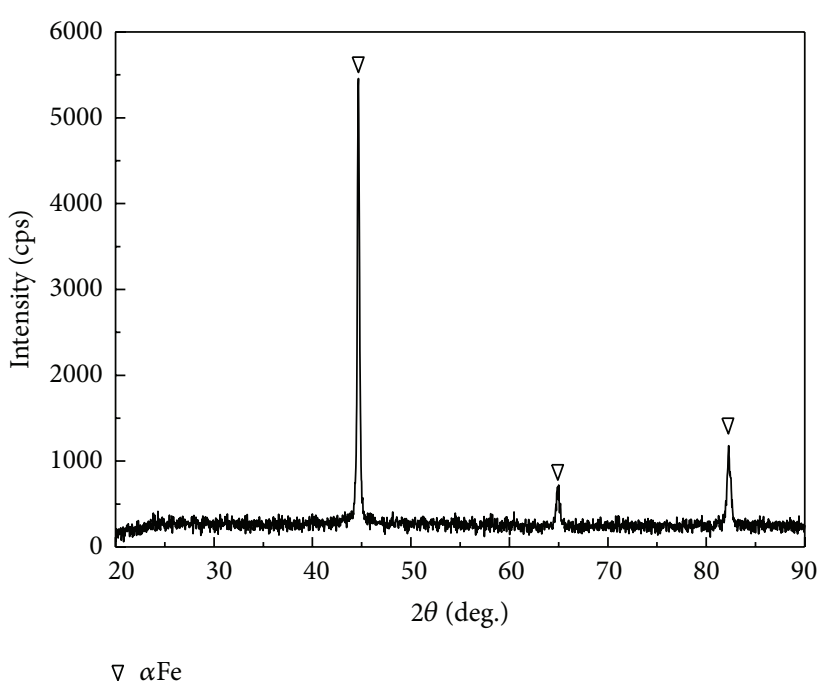

(c)

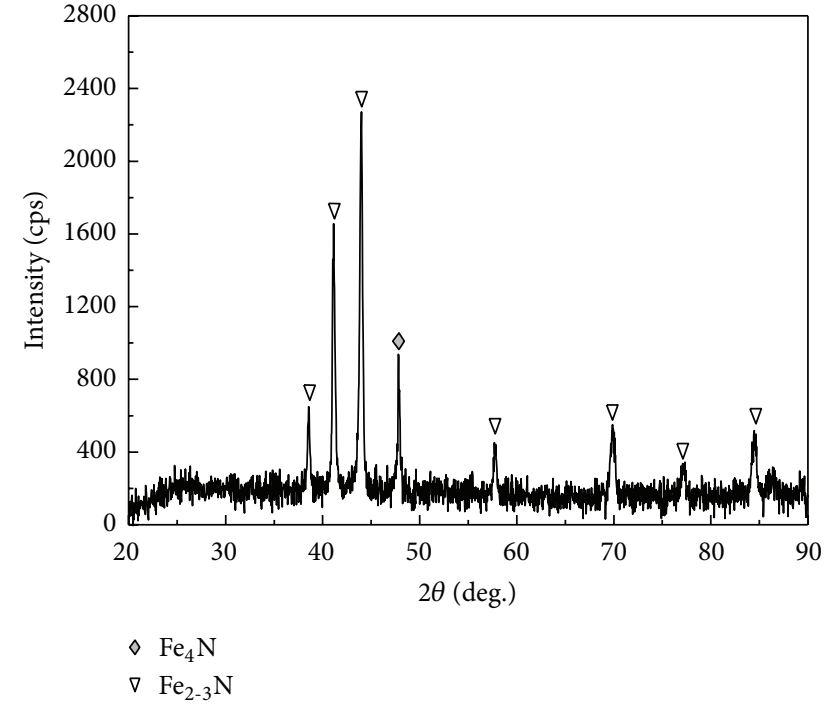

(b)

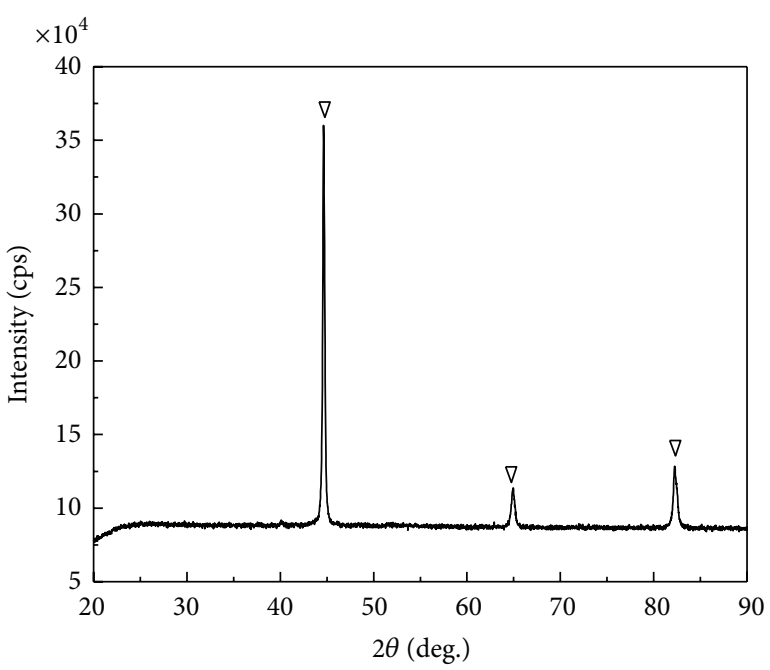

$\nabla \alpha \mathrm{Fe}$

(d)

FIGURE 4: X-ray diffraction patterns of (a) CN, (b) CN with the oxide layer polished, (c) CNP, and (d) UCN.

high stress [15]. Under the fatigue test conditions used in this work, the faint effect of residual compressive stress on the bottom of the indentation is completely lost. As a result, the crack initiates from the bottom of the indentation and leads to failure of the specimen (Figure 8). The differences between the experimental fatigue limits and the theoretical values can be neglected, and the fatigue limit of the indented UCN can be predicted using (2), identical to the cases of inclusions and notches with the same dimensions.

The fatigue limit of the $\mathrm{CN}$ is $280 \mathrm{MPa}$, which is $12 \%$ higher than that of the UCN. The fatigue limit of the indented $\mathrm{CN}$ decreases sharply with increasing indentation dimension. When the square root of the indentation projected area is greater than $300 \mu \mathrm{m}$, the fatigue limit of the $\mathrm{CN}$ is lower than that of the UCN. The equation proposed by Murakami and
Usuki [12] is not applicable here because of the gradient of hardness of the case layer.

The fatigue crack of the smooth $\mathrm{CN}$ originates from the surface (Figure 9(a)). Pores in the oxide layer and in the compound layer act as the crack initiation sites. The fracture surface of the compound layer is flat, without any signs of plastic deformation (Figure 9(b)). At the intersection of the compound layer and the diffusion layer, the brittle fracture surface is displaced by plastic striations. Premicrocracks in the compound layer of the indented $\mathrm{CN}$ propagate into the specimen (Figure 10).

During the carbonitriding process, a compound layer formed on the surface of the $\mathrm{CN}$ with a mixture of $\mathrm{Fe}_{4} \mathrm{~N}$ and $\mathrm{Fe}_{2-3} \mathrm{~N}$ (Figure 4(b)). Both of the two phases are hard and brittle. Figure 3 suggests that the strength of the diffusion 


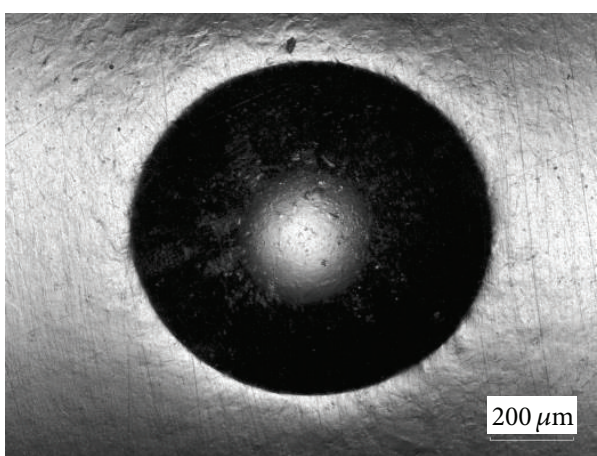

(a)

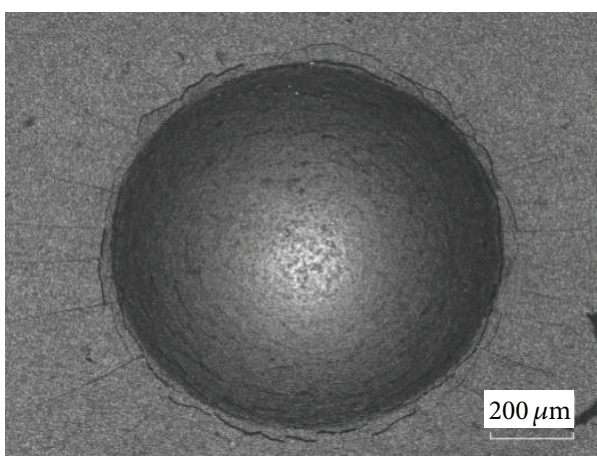

(c)

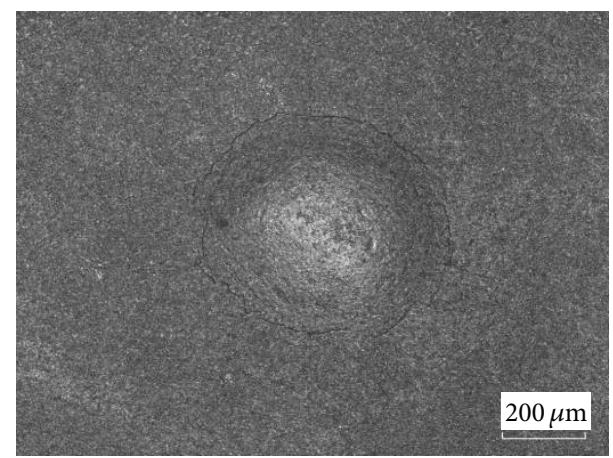

(b)

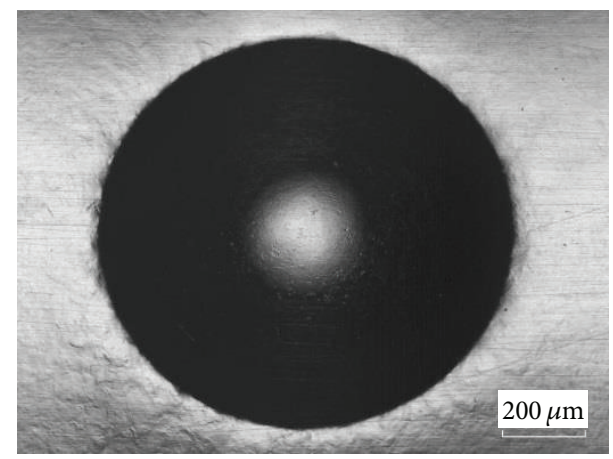

(d)

FIGURE 5: Morphologies of the indentations: (a) indentation on UCN under $100 \mathrm{~N}$, (b) indentation on CN under $62.5 \mathrm{~N}$, (c) indentation on $\mathrm{CN}$ under $187.5 \mathrm{~N}$, and (d) indentation on CNP under $187.5 \mathrm{~N}$.

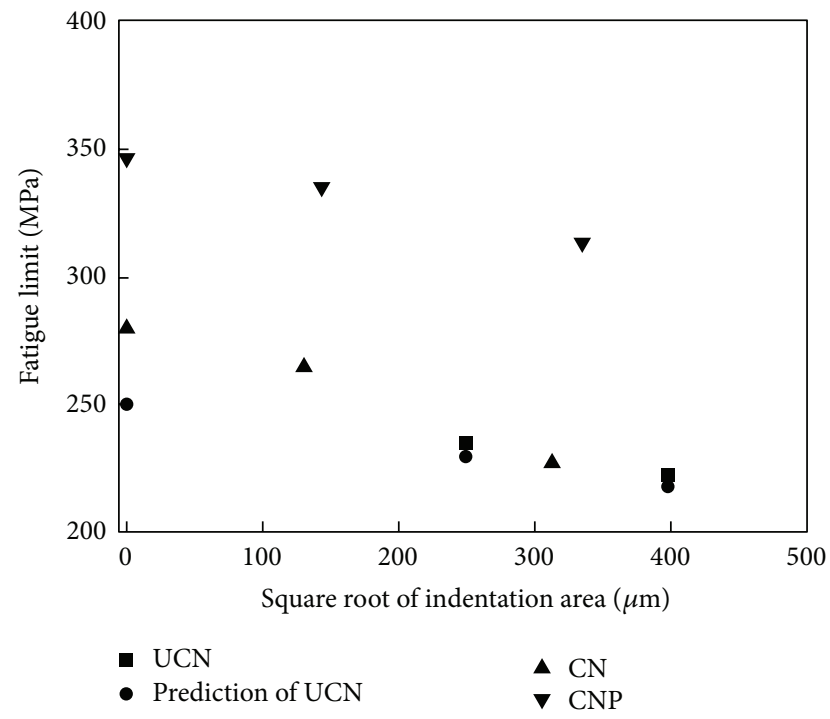

Figure 6: The relationship between the fatigue limit and the indentation size.

layer is also improved according to the relationship between strength and hardness. For a smooth ductile specimen, as is well accepted by researchers, the cracks nucleate in the form of intrusion and extrusion of the surface material. The hardened layer with a higher yield stress delays the crack initiation. Residual compressive stress introduced by volume expansion and lattice distortion in the hardened layer also contributes to the enhancement of the fatigue limit of the $\mathrm{CN}$. However, the pores in the oxide layer roughen the surface of the CN specimen and serve as stress concentration sites, as shown in Figure 9(b). In addition, voids are observed on the top of the compound layer induced by the emission of nitrogen gas. These surface defects weaken the positive effect of carbonitriding on the fatigue strength, even decreasing the rotating-bending fatigue limit of high-strength steel, as reported by Farrahi and Ghadbeigi [16]. The fatigue limit of the $\mathrm{CN}$ specimen is only enhanced by $12 \%$ with respect to that of the smooth UCN specimen, and cracks initiate from the surface defects of the $\mathrm{CN}$ (Figure 9(a)).

When a small indentation was introduced in the $\mathrm{CN}$, radial-median microcracks formed in the indentation caused by the rupture of the hard and brittle compound layer, as observed in Figure 5(b). The surface integrity and stress condition are affected by the presence of indentation and microcracks. The precracks propagate under cyclic stress and lead to failure of the specimen (Figure 10). The fatigue limit is reduced by a small margin (Figure 6), but it remains higher than that of the UCN. When the indentation is larger, as shown in Figure 5(c), the compound layer on the surface of the indentation is crushed, and radial cracks form around the indentation. Some of the radial cracks, which are perpendicular to the axial direction, are fatal for the fatigue strength. Thus, the fatigue limit exhibits a sharp decrease, even lower than that of the UCN with a defect with the same 


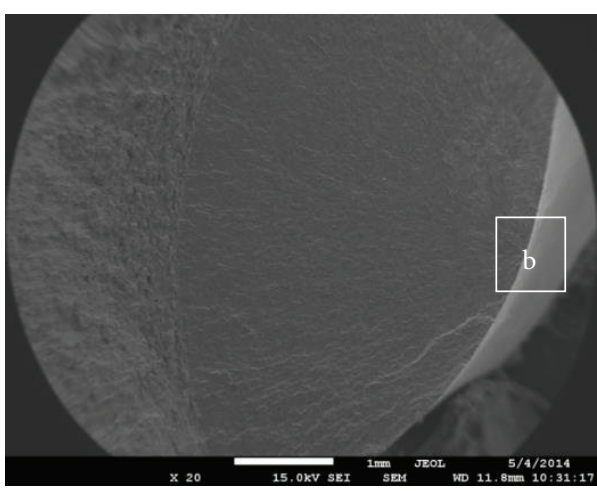

(a)

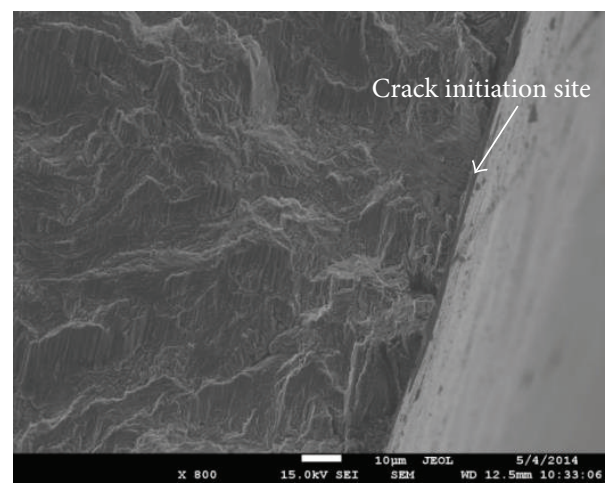

(b)

FIGURE 7: Typical fracture surface of the smooth UCN: (a) fracture surface and (b) crack initiation site.

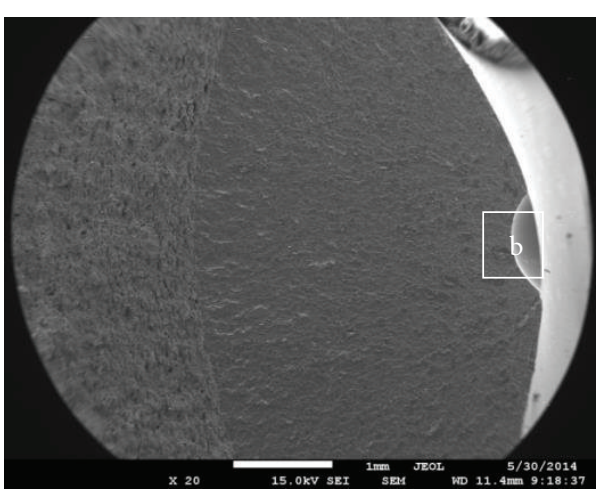

(a)

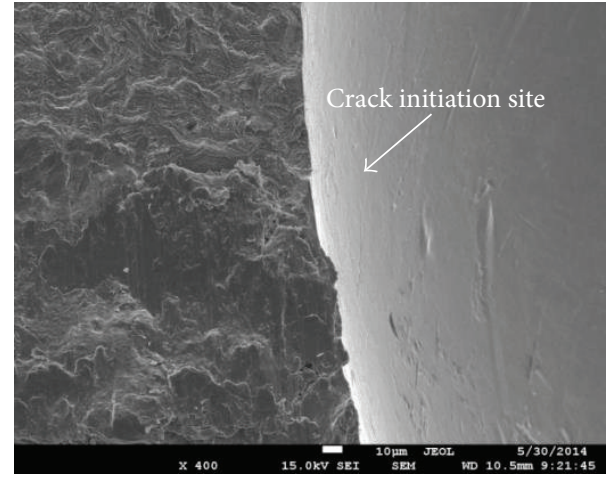

(b)

Figure 8: Typical fracture surface of the indented UCN: (a) fracture surface and (b) crack initiation site.

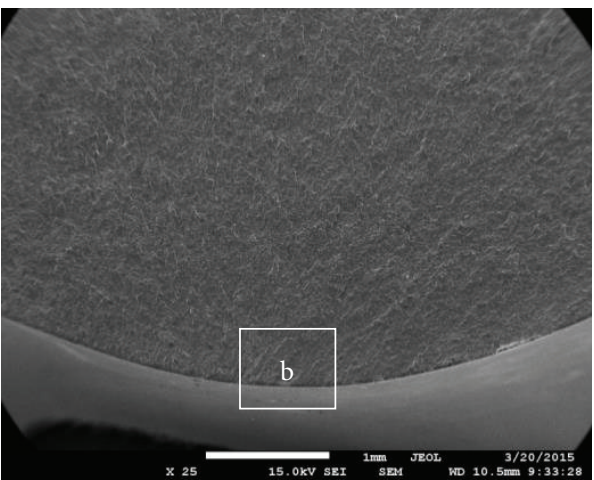

(a)

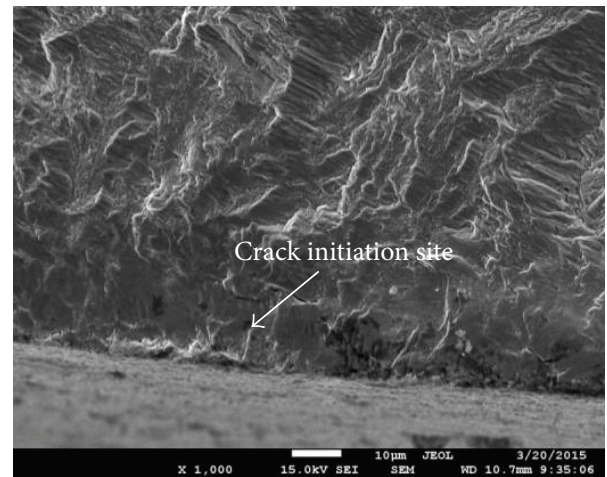

(b)

FIGURE 9: Fracture surface of the CN: (a) fracture surface and (b) crack initiation site.

dimensions (Figure 6). In fact, the effective area of the defect is enlarged if the precracks are considered.

The fatigue limit of the CNP is improved by $40 \%$ and $24 \%$ with respect to those of the $\mathrm{UCN}$ and the $\mathrm{CN}$, respectively. Although the fatigue limit of the CNP decreases when the projected area of indentation is larger, it remains higher than those of the UCN and the CN. The failure of the CNP still starts from the surface, as shown in Figure 11(a). Notably, cracks originate from several sites (Figure 11(b)). Cracks of the indented CNP, similar to the other indented specimens, propagate from the bottom of the indentation with the largest stress concentration (Figure 12).

After the compound layer is removed by mechanical polishing, the surface of specimen is free of the defects left by carbonitriding and the fatigue strength exhibits an improvement of $40 \%$ in comparison with that of the UCN. During 


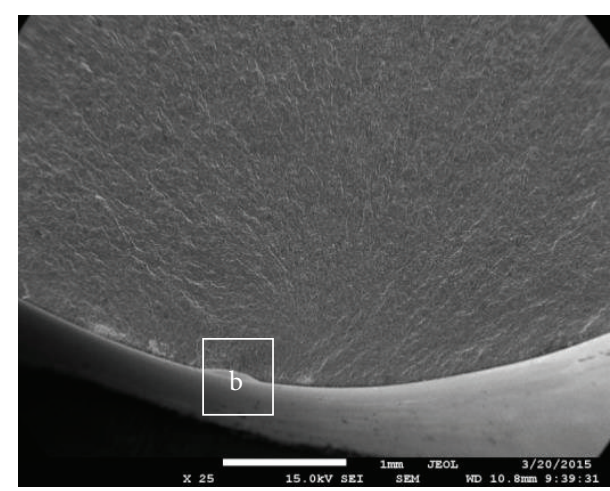

(a)

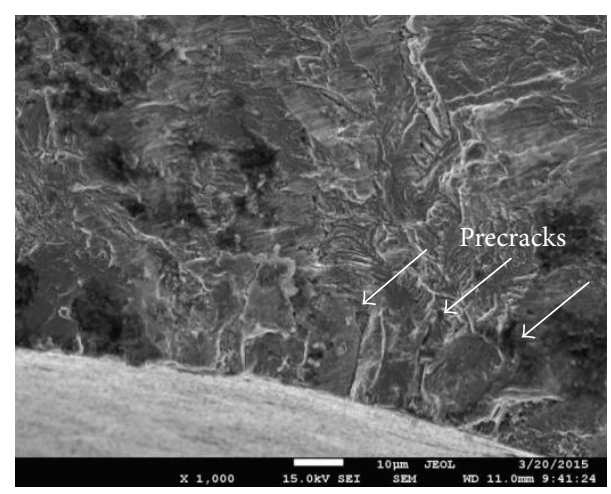

(b)

FIGURE 10: Fracture surface of the indented CN: (a) fracture surface and (b) crack initiation site on the bottom of the indentation.

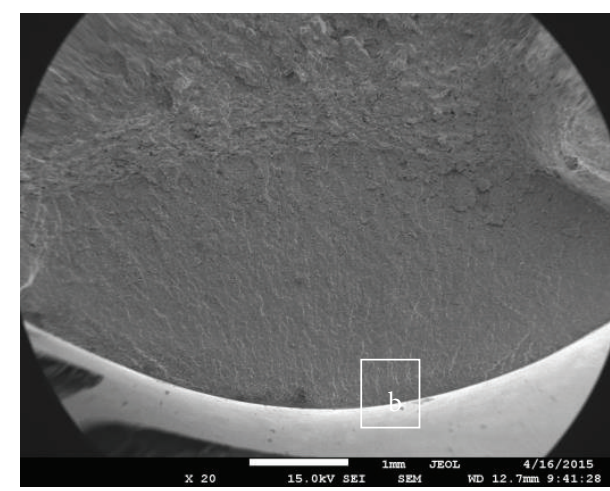

(a)

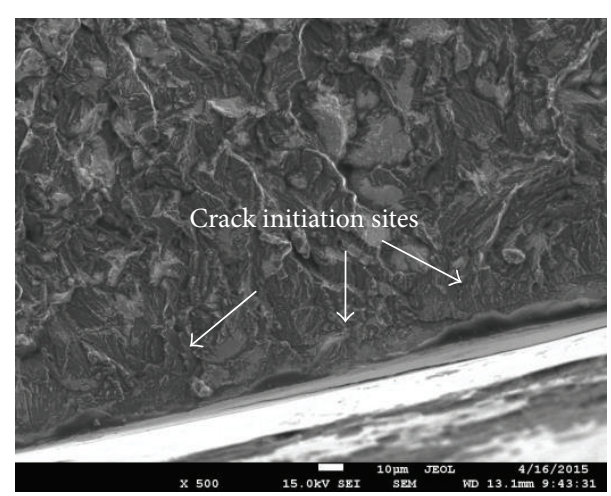

(b)

FIgURE 11: Fracture surface of the CNP: (a) fracture surface and (b) crack initiation sites.

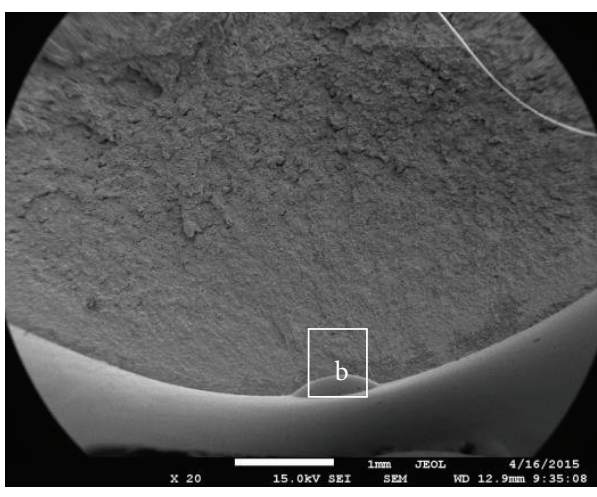

(a)

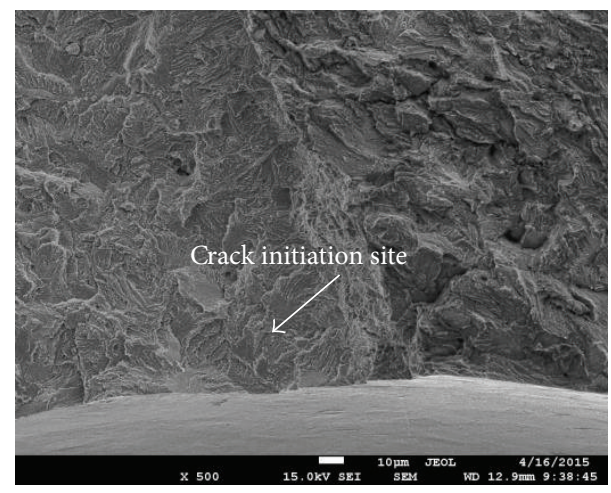

(b)

FIGURE 12: Fracture surface of the indented CNP: (a) fracture surface and (b) crack initiation sites on the bottom of the indentation.

mechanical polishing, the mechanical property and stress condition of the top layer may well be altered by grinding. The cracks of the CNP originate from the surface. Although the cracks have been reported to start from internal inclusions in some works, in fact, the location of a crack initiation site is controlled by several factors, including the surface condition, stress amplitude, and material cleanliness [17].
The indented CNP is free from precracks caused by indentation, and the fatigue limit gradually decreases with increasing indentation size. The fatigue limit is still greater than $300 \mathrm{MPa}$, even when the size of the defect reaches $300 \mu \mathrm{m}$. The crack initiation site is located at the bottom of the indentation for stress concentration (Figure 12), as is the case of the indented UCN. 
The compound layer does not significantly affect the fatigue strength, especially in the case of a defect-free compound layer; however, this lack of effect of the compound layer is not the case for a specimen under impact $[6,18]$. Removal of the compound layer can inhibit the formation of microcracks and delamination when a carbonitrided specimen is exposed to an impact force. However, removing the compound layer or not should not neglect the working condition of carbonitrided components.

\section{Conclusions}

In this study, artificial indentations were produced on UCN, $\mathrm{CN}$, and CNP specimens of S38C plain steel. The fatigue property of specimens with and without indentation was assessed. The main results are summarized as follows:

(i) The fatigue limit of the S38C specimen (250 MPa) was increased by $12 \%$ after carbonitriding. When the compound layer was removed, the fatigue strength was enhanced by up to $40 \%$ compared to that of the untreated specimen.

(ii) The fatigue limit of the UCN decreased with increasing indentation size. The fatigue strength of the indented CN decreased sharply because of the microcracks caused by crushing of the compound layer, whereas the fatigue strength of the indented CNP gradually decreased and remained higher than those of the indented UCN and the indented $\mathrm{CN}$ with the same-sized indentation.

(iii) The fatigue cracks of the UCN and the CNP started from the surface, whereas that of the $\mathrm{CN}$ originated from a defect (e.g., pores in the oxide layer and voids in the compound layer). When indentations were introduced, the UCN and the CNP failed, with a fatigue crack originating from the bottom of the indentation because of the stress concentration effect. The precracks in the compound layer caused by indentation led to failure of indented $\mathrm{CN}$ under cyclic stress.

\section{Conflict of Interests}

The authors declare that there is no conflict of interests regarding the publication of this paper.

\section{Acknowledgments}

The authors acknowledge CSR Qingdao Sifang Co., Ltd., for providing material and financial support. This work was also supported by Open Research Funds of The State Key Laboratory of Materials Forming and Mould Technology (P2015-10). Thanks are due to Professor Chuan Yang for carbonitriding treatment.

\section{References}

[1] F. Yildiz, A. F. Yetim, A. Alsaran, A. Çelik, and I. Kaymaz, "Fretting fatigue properties of plasma nitrided AISI $316 \mathrm{~L}$ stainless steel: experiments and finite element analysis," Tribology International, vol. 44, no. 12, pp. 1979-1986, 2011.

[2] D.-C. Wen, "Erosion and wear behavior of nitrocarburized DC53 tool steel," Wear, vol. 268, no. 2-3, pp. 629-636, 2010.

[3] L.-H. Chiu, C.-H. Wu, and H. Chang, "Wear behavior of nitrocarburized JIS SKD61 tool steel," Wear, vol. 253, no. 7-8, pp. 778-786, 2002.

[4] J. Wan and A. Fatemi, "Cyclic deformation and fatigue behaviour of ion-nitrided steel," International Journal of Fatigue, vol. 17, no. 1, pp. 15-24, 1995.

[5] G. Castro, A. Fernández-Vicente, and J. Cid, "Influence of the nitriding time in the wear behaviour of an AISI H13 steel during a crankshaft forging process," Wear, vol. 263, no. 7-12, pp. 13751385, 2007.

[6] A. Alsaran, M. Karakan, and A. Çelik, "The investigation of mechanical properties of ion-nitrided AISI 5140 low-alloy steel," Materials Characterization, vol. 48, no. 4, pp. 323-327, 2002.

[7] M. A. Terres and H. Sidhom, "Fatigue life evaluation of 42CrMo4 nitrided steel by local approach: equivalent strainlife-time," Materials \& Design, vol. 33, no. 1, pp. 444-450, 2012.

[8] Y. Ohue and K. Matsumoto, "Sliding-rolling contact fatigue and wear of maraging steel roller with ion-nitriding and fine particle shot-peening," Wear, vol. 263, no. 1-6, pp. 782-789, 2007.

[9] N. Limodin and Y. Verreman, "Fatigue strength improvement of a 4140 steel by gas nitriding: influence of notch severity," Materials Science and Engineering A, vol. 435-436, pp. 460-467, 2006.

[10] I. Fernández-Pariente, S. Bagherifard, M. Guagliano, and R. Ghelichi, "Fatigue behavior of nitrided and shot peened steel with artificial small surface defects," Engineering Fracture Mechanics, vol. 103, pp. 2-9, 2013.

[11] K. Maenosono, "Effect of ion-nitriding on low cycle impact fatigue strength in SMS0 steel," Japan Society of Material Science, vol. 39, pp. 157-161, 1990.

[12] Y. Murakami and H. Usuki, "Quantitative evaluation of effects of non-metallic inclusions on fatigue strength of high strength steels. II: fatigue limit evaluation based on statistics for extreme values of inclusion size," International Journal of Fatigue, vol. 11, no. 5, pp. 299-307, 1989.

[13] S. Bagherifard, R. Ghelichi, and M. Guagliano, "Mesh sensitivity assessment of shot peening finite element simulation aimed at surface grain refinement," Surface \& Coatings Technology, vol. 243, pp. 58-64, 2014.

[14] S. Bhat and R. Patibandla, "Metal fatigue and basic theoretical models: a review," in Alloy Steel-Properties and Use, InTech, 2011.

[15] G. I. Mylonas and G. Labeas, "Numerical modelling of shot peening process and corresponding products: residual stress, surface roughness and cold work prediction," Surface and Coatings Technology, vol. 205, no. 19, pp. 4480-4494, 2011.

[16] G. H. Farrahi and H. Ghadbeigi, "An investigation into the effect of various surface treatments on fatigue life of a tool steel," Journal of Materials Processing Technology, vol. 174, no. 1-3, pp. 318-324, 2006. 
[17] K. Genel, M. Demirkol, and M. Çapa, "Effect of ion nitriding on fatigue behaviour of AISI 4140 steel," Materials Science and Engineering A, vol. 279, no. 1-2, pp. 207-216, 2000.

[18] F. Ashrafizadeh, "Influence of plasma and gas nitriding on fatigue resistance of plain carbon (Ck45) steel," Surface and Coatings Technology, vol. 174-175, pp. 1196-1200, 2003. 

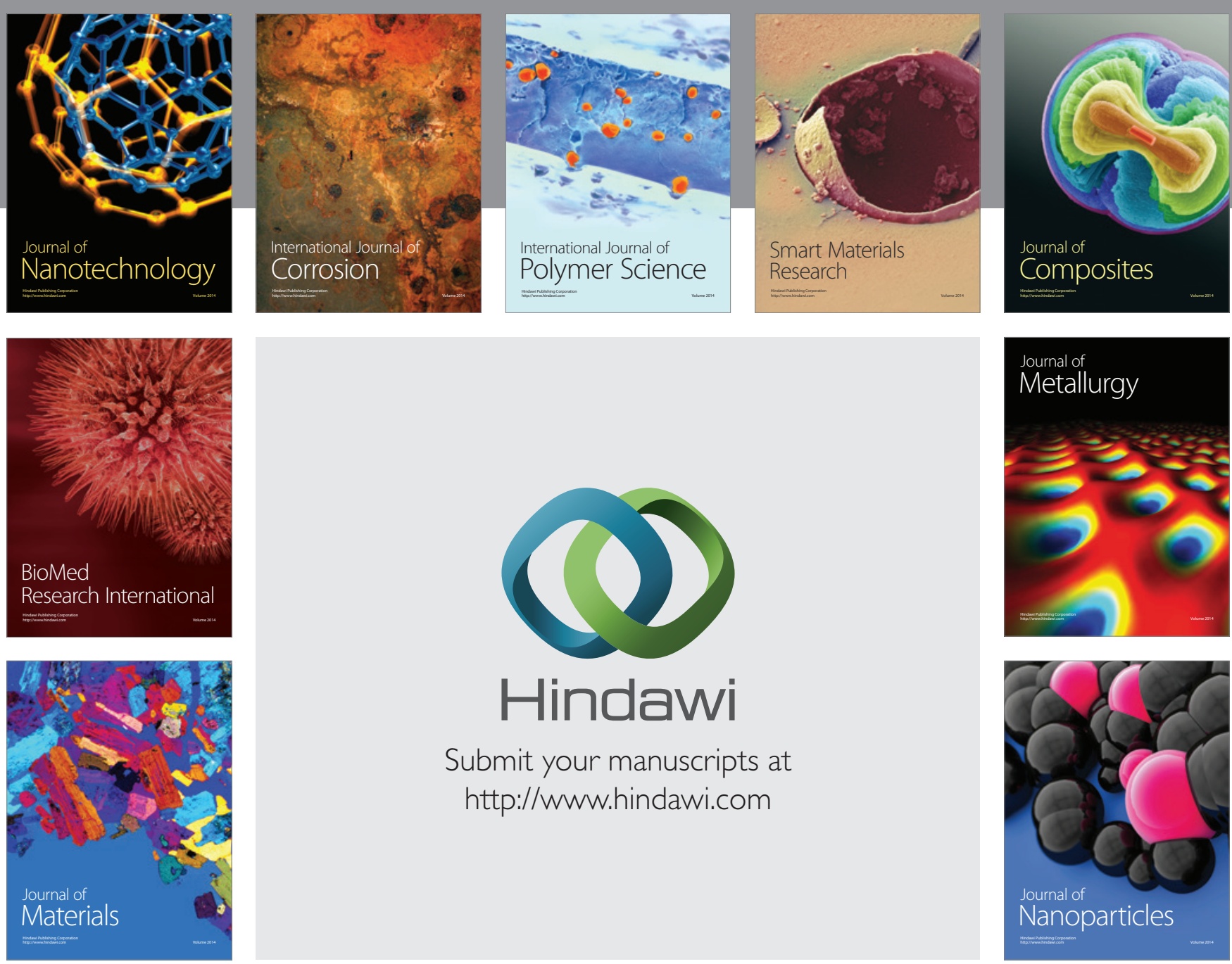

Submit your manuscripts at http://www.hindawi.com
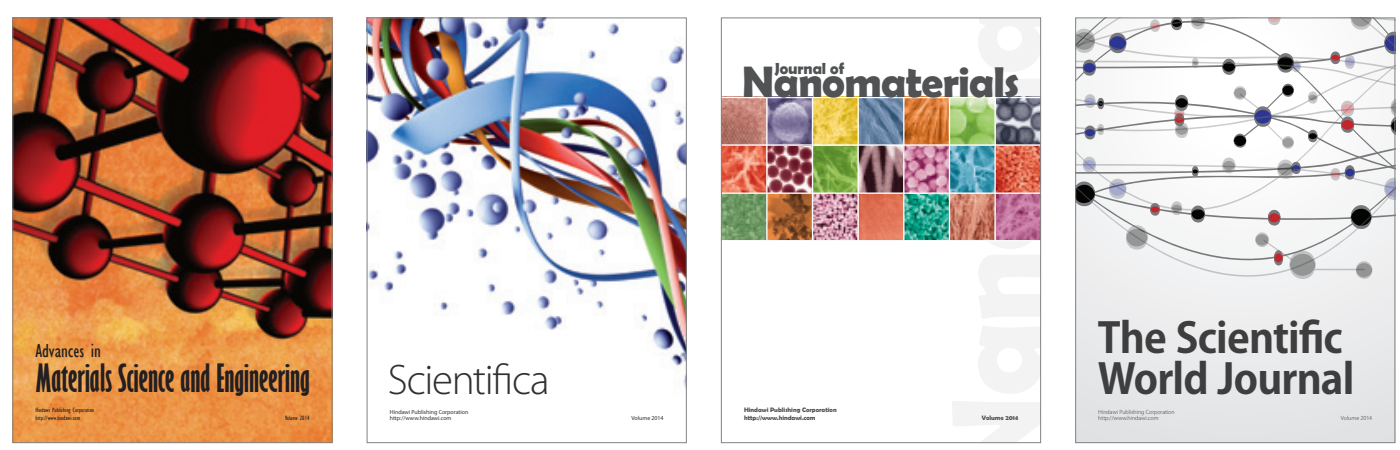

\section{The Scientific World Journal}
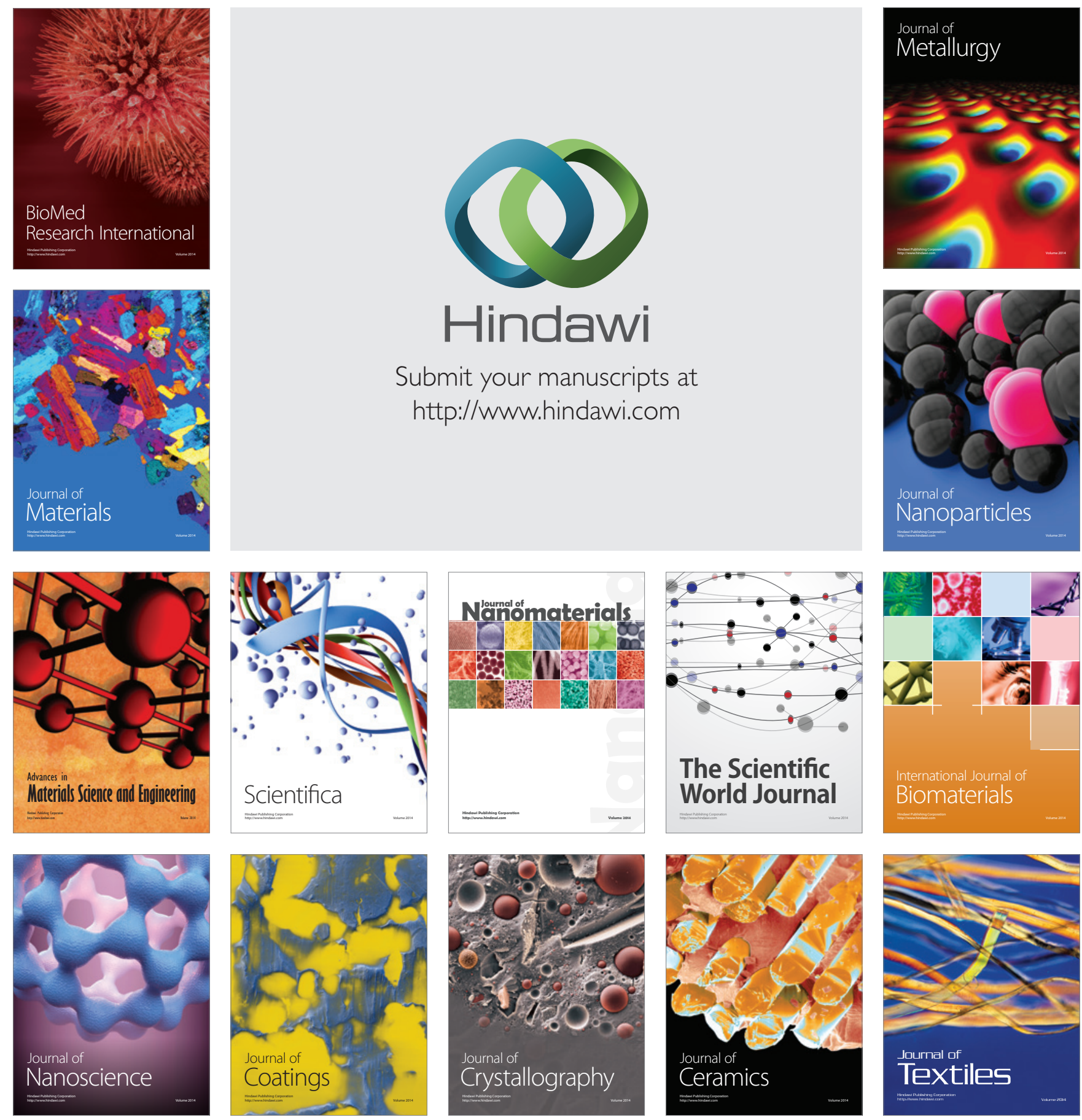